\title{
Assessment of Pain Outcome and Amount of Analgesic Required Post Operatively After Instillation of Bupivacaine amongst Pre Incisional Vs. Postincisional Vs. Control Groups
}

\author{
Nippun Chhakarvarty ${ }^{1}$, Umesh Chhabra ${ }^{2}$, Vikram Singh ${ }^{3}$, Gopal Singhal ${ }^{4}$ \\ ${ }^{1}$ Assistant Professor, Department of Surgery, Maharaja Agrasen Medical College, Agroha, Hisar, Haryana, India, ${ }^{2}$ Associate Professor, Department of Surgery, \\ Maharaja Agrasen Medical College, Agroha, Hisar, Haryana, India, ${ }^{3}$ Medical Officer, Civil Hospital, Adampur, Hisar, Haryana, India, ${ }^{4}$ Professor, Department of \\ Surgery, Maharaja Agrasen Medical College, Agroha, Hisar, Haryana, India.
}

\section{Abstract}

Background: Effective postoperative pain control is an essential component for care of surgical patients. Although opioid analgesics are effective in treating postoperative pain, concerns regarding their ability to increase nausea, vomiting and to produce respiratory depression have limited their use during laparoscopic procedures. The study aimed to provide impetus for further research and help in performance of laparoscopic cholecystectomy as a day care procedure. Subjects and Methods: The present study was conducted on a group of 180 patients diagnosed to have symptomatic cholelithiasis and who underwent elective laparoscopic cholecystectomy. In one group, pre-incisional local infiltration of $20 \mathrm{ml} 0.5 \%$ bupivacaine at the port sites with intraperitonial installation of $10 \mathrm{ml} 0.25 \%$ bupivacaine was done throughout all the layers of the abdominal wall (till peritoneum). In group 2, local infiltration of $20 \mathrm{ml} 0.5 \%$ bupivacaine at the port sites with intraperitonial installation of $10 \mathrm{ml} 0.25 \%$ bupivacaine was done after the completion of surgical procedure, and just before the closure of skin. The analysis was done using one way ANOVA \& Post HOC test (Scheffe's HSD) \& Chi square tests. Parameters studied are side effects like nausea/ vomiting and the additional need of rescue analgesia along with elapsed time for 1st rescue analgesia. Results: Our patients in both the study groups received the first analgesic drug much later ( 6 hours postoperatively) as compared to the control group ( 2.3 hours post operatively). The total analgesic requirement post operatively was also lower in the study group with respect to the control group. (150 mg vs $300 \mathrm{mg}$ of inj Diclofenac sodium) There was no significant difference in the incidence of shoulder tip pain amongst the three groups. 11 out of 180 patients in the study group experienced post-operative nausea while 6 out of 60 patients in the control group experienced nausea. Conclusion: To conclude, technique of instillation of bupivacaine at the port sites in laparoscopic cholecystectomy is simple, safe and without adverse effects. It is likely to be cost effective, because it decreases post-operative usage of NSAIDS or opioids, and helps in better resource utilization for treatment of postoperative pain and also useful for patient to provide a more comprehensive and comfortable post-operative period.

Keywords: Bupivacaine; Laparoscopic Cholecystectomy; Pre-Incisional Local Infiltration.

Corresponding Author: Dr. Umesh Chhabra, Associate Professor, Department of Surgery, Maharaja Agrasen Medical College, Agroha, Hisar, Haryana, India.

Received: October 2019

Accepted: November 2019

\section{Introduction}

During last ten years postsurgical visceral pain and intense nociceptive somatic pain in immediate post-surgical period is considered as, the most important endocrinal and neurohumoral disorder. That period is therefore characterized by increased catabolism, increased secretion of stress hormones, increased stress of the cardiovascular system, lung function disorder, occurrence of hypercoagulability, fibrinolysis decline, immunological suppression, paralytic ileus and post-surgical nausea and vomiting. ${ }^{[1]}$

One of the main cause of pain is trauma to the abdominal wall and visceral organs by surgical instruments. There is a linear inverse relationship between abdominal compliance and severity of postoperative pain at the time of laparoscopy. Therefore, abdominal distention should better be done slowly with adequate muscle relaxation to ensure suitable abdominal compliance. Prolonged presence of shoulder tip pain suggests excitation of phrenic nerve, caused by persistence of gas in the abdomen after laparoscopic procedure. There is statistically significant correlation between the $\mathrm{CO} 2$ pressure and pain score, and this pain can be reduced by the aspiration of the gas under the diaphragm. ${ }^{[2]}$

Effective postoperative pain control is an essential component for care of surgical patients. Inadequate pain control may result in increased morbidity or mortality. Evidence suggests that surgery suppresses the immune system and this suppression is proportionate to invasiveness of the surgery. Good analgesia can reduce this deleterious effect. Data available indicate that afferent neural blockade 
with local anesthetics is the most effective analgesic technique. Next in order of effectiveness are high-dose opioids, epidural opioids and clonidine, patient controlled analgesia, and nonsteroidal anti-inflammatory agents. ${ }^{[3]}$ Although opioid analgesics are effective in treating postoperative pain, concerns regarding their ability to increase nausea, vomiting and to produce respiratory depression have limited their use during laparoscopic procedures ${ }^{[4]}$ Non-steroidal anti-inflammatory drugs (NSAID) block the synthesis of prostaglandins by inhibition of enzyme cyclo-oxygenase. In major surgery combination of NSAIDs and opioids provide better quqlity of analgesic as compaired to opioid alone. Moreover, it has consistently been shown that NASIDs given soon after major surgery reduces opioid requirements by about one third. ${ }^{[5]}$

There is dearth of studies on timing of giving the local anaesthetic agent, whether to give it before incision or to instill it just before closure of the port site wounds. The study aimed to provide impetus for further research and help in performance of laparoscopic cholecystectomy as a day care procedure.

\section{Subjects and Methods}

The present study was conducted on a group of 180 patients diagnosed to have symptomatic cholelithiasis and who underwent elective laparoscopic cholecystectomy under General Anaesthesia in Department of Surgery at Maharaja Agrasen Medical College, Agroha, Hisar. The whole procedure and risks involved were fully explained to the patient and well informed and written consent in vernacular language was taken. In group 1, pre-incisional local infiltration of $20 \mathrm{ml} 0.5 \%$ bupivacaine at the port sites with intraperitonial installation of $10 \mathrm{ml} 0.25 \%$ bupivacaine was done throughout all the layers of the abdominal wall (till peritoneum). In group 2, local infiltration of $20 \mathrm{ml} 0.5 \%$ bupivacaine at the port sites with intraperitonial installation of $10 \mathrm{ml} 0.25 \%$ bupivacaine was done after the completion of surgical procedure, and just before the closure of skin. Bupivacaine instillation in both groups $1 \& 2$ was allocated according to the diameter of the trocar; $7 \mathrm{ml}$ for $10 \mathrm{~mm}$ port and $3 \mathrm{ml}$ for $5 \mathrm{~mm}$ port and $10 \mathrm{ml}$ intraperitonial over liver site. In group 3, no local infiltration was done and was treated as control group. The study was evaluated using Visual analog scale for period of 24 hours post-operatively. The analysis of our study was performed using statistical analysis tools, initially crosstabs procedure was performed followed by one way ANOVA \& Post HOC test (Scheffe's HSD) \& Chi square tests as and when indicated.

\section{Inclusion criteria}

All patients scheduled for undergoing laparoscopic cholecystectomy, with ultrasonography evidence with age $\geq$ 18 years and ASA class I or II.

Patients unwilling to participate, conversion of laparoscopic cholecystectomy into open cholecystectomy and patients who fail to understand the pain assessment tool were not included in the study. Following parameters were followed at different time intervals i.e. at $0 \mathrm{hrs}, 30 \mathrm{mins}, 4 \mathrm{hrs}, 6 \mathrm{hrs}$, $12 \mathrm{hrs} \& 24 \mathrm{hrs}$ postoperatively and recorded in the proforma;

1. Intensity of pain during rest and during movement on bed.

2. Pulse Rate

3. Blood Pressure

4. Respiratory Rate

5. Temperature

6. Side effects like Nausea/ Vomiting

7. The additional need of rescue analgesia along with elapsed time for 1st rescue analgesia

\section{Results}

The mean duration of hospitalization amongst all the three groups was 3.58 days [Table 1]. Group 1 was 3.46 days, group 2 was 3.58 days and group 3 was 3.72 days. The mean range was 2 - 7days. There was no statistical difference in the mean duration of hospitalization amongst the three groups. $(\mathrm{F}=1.748, \mathrm{P}=0.179)$.

The range for timing of giving first analgesic was between 0.5 -24 hours in groups $1 \& 2$ and $0.5-18$ Hours in group 3 . In group 1 and 2 some of the patients need analgesia Immediately after extubation though bupivacaine instillation was also done. The mean timing for giving first shot of analgesic was comparable in the preincisional \& Pre closure group i.e. $5.83 \& 4.55$ hours respectively, however it was significantly early in the control group i.e. 2.66 hours $(p=<0.001)$ [Table 2, Figure 1]. Bupivacaine instillation at port site in both the groups significantly delays the time needed for giving the first analgesic dosage. The average amount of total analgesic used in the control group 3 was significantly higher compared to the other two groups 1 and 2 [Table 3, Figure 2]. But there was no significant difference among group $1 \& 2$ in terms of total number of analgesic dosages $(\mathrm{p}>0.05)$.

Postoperative shoulder tip pain was present in all three groups, 4 patients in the pre incisional group, 2 in the pre closure group \& 6 patients in the control group complained of sholuder tip pain postoperatively [Table 4]. However chi square test yielded that the results were insignificant with $\mathrm{p}$ value $=0.392$.

Table 1: Mean duration of hospitalization

\begin{tabular}{|c|c|c|c|c|c|c|}
\hline Group & $\mathbf{N}$ & Range & $\begin{array}{l}\text { Duration (Hours) } \\
\text { Mean } \pm S D\end{array}$ & ANOVA\# & Comparison & $P$ value\# \\
\hline Group 1 & 60 & $2-5$ & $3.46 \pm 0.90$ & \multirow{3}{*}{$\begin{array}{l}\mathrm{F}=1.748 \\
\mathrm{P}=0.179 \\
\mathrm{NS}\end{array}$} & Group 1 vs 2 & $0.181 \mathrm{NS}$ \\
\hline Group 2 & 60 & $2-5$ & $3.58 \pm 1.06$ & & Group 1 vs 3 & $0.352 \mathrm{NS}$ \\
\hline Group 3 & 60 & $3-7$ & $3.72 \pm 1.18$ & & Group 2 vs3 & $0.917 \mathrm{NS}$ \\
\hline
\end{tabular}

p $>0.05$; Not significant; *p $<0.05$; Significant 
Table 2: Mean Time to give first analgesic

\begin{tabular}{|c|c|c|c|c|c|c|}
\hline Group & $\mathbf{N}$ & Range & $\begin{array}{l}\text { Time } \\
\text { Mean } \pm \text { SD }\end{array}$ & ANOVA\# & Comparison & P Value\# \\
\hline Group 1 & 60 & $0-24$ & $5.63 \pm 6.36$ & \multirow{3}{*}{$\begin{array}{l}\mathrm{F}= \\
18-431 ; \\
\mathrm{P}<0.001 * *\end{array}$} & Group 1 vs 2 & $0.977 \mathrm{NS}$ \\
\hline Group 2 & 60 & $0-24$ & $5.92 \pm 6.03$ & & Group 1 vs 3 & $<0.001 * *$ \\
\hline Group 3 & 60 & $0.5-18$ & $2.34 \pm 4.15$ & & Group 2 vs 3 & $<0.001 * *$ \\
\hline
\end{tabular}

p $>0.05$; Not significant; ** $\mathrm{p}<0.001$; Highly Significant

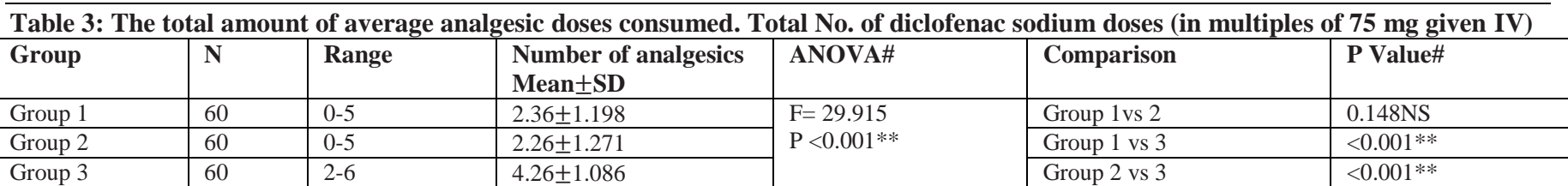

$\mathrm{p}>0.05$; Not significant; **p $<0.001 ;$ Highly Significant

Table 4: Incidence of shoulder tip pain

\begin{tabular}{|l|l|l|l|}
\hline Shoulder tip pain & Group 1 & Group 2 & Group 3 \\
\hline Present & $5(9.1 \%)$ & $2(3.3 \%)$ & $6(10 \%)$ \\
\hline Absent & $55(90.9 \%)$ & $58(96.7 \%)$ & $54(90 \%)$ \\
\hline $\mathrm{x}^{2}=1.875 ;$ df $=2 ; \mathrm{p}=0.392 ;$ Not Significant
\end{tabular}

$\mathrm{x}^{2}=1.875 ; \mathrm{df}=2 ; \mathrm{p}=0.392 ;$ Not Significant

Table 5: Incidence of postoperative Nausea

\begin{tabular}{|l|l|l|l|}
\hline Nausea & Group 1 & Group 2 & Group 3 \\
\hline Present & $2(3.33 \%)$ & $3(5 \%)$ & $6(10 \%)$ \\
\hline Absent & $58(96.67 \%)$ & $57[95 \%]$ & $54(90 \%)$ \\
\hline
\end{tabular}

$\mathrm{x}^{2}=8.276 ; \mathrm{df}=2 ; \mathrm{p}=0.016$ Significant

\begin{tabular}{|c|c|c|c|}
\hline \multicolumn{4}{|c|}{ Table 6: Incidence of post-operative vomiting } \\
\hline Vomiting & Group 1 & Group 2 & Group 3 \\
\hline Present & 0 & 0 & $2(3.33 \%)$ \\
\hline Absent & $60(100 \%)$ & $60(100 \%)$ & $58(97.67 \%)$ \\
\hline
\end{tabular}

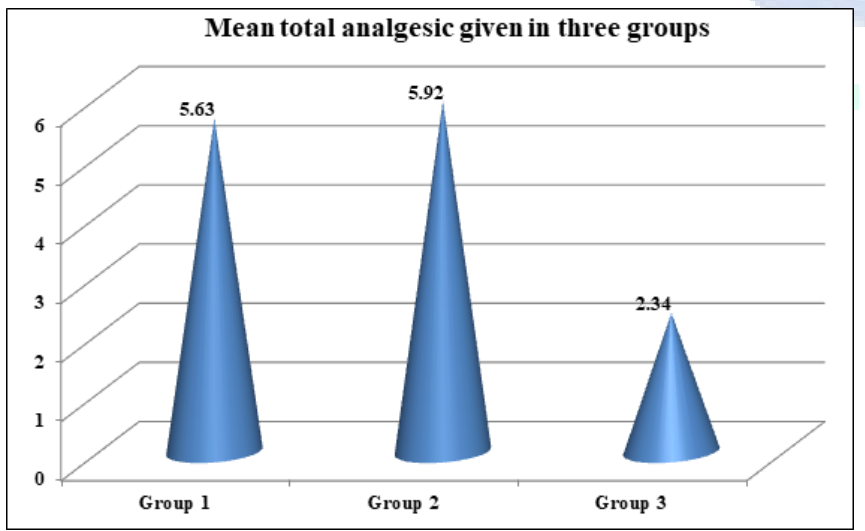

Figure 1: Mean timing for giving first analgesic (in hours)

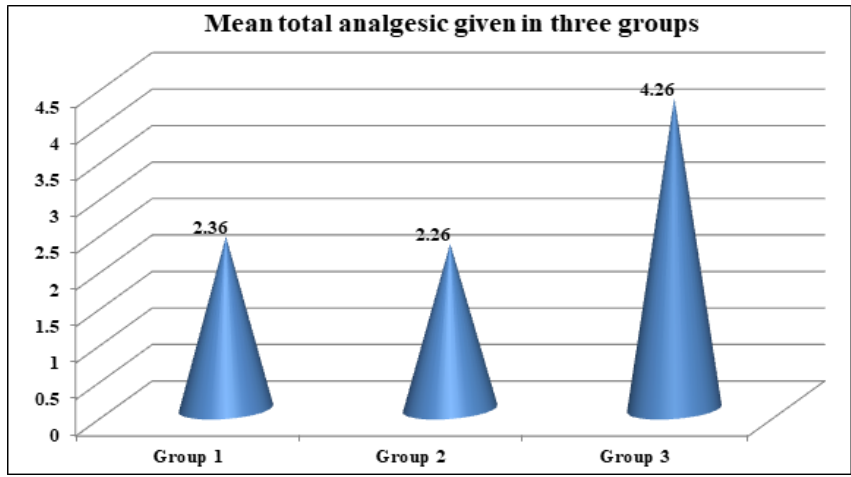

Figure 2: Total amount of average analgesic doses consumed
Post-operative nausea was seen in 6 patients in the control group, 5 patients in preincisional and preclosure group [Table 5]. Hence, bupivacaine instillation post-operatively has significant effect on postoperative nausea. $(p=0.016)$. None of the patient experience postoperative vomiting [Table 6]. No side effects were observed with the use of Bupivacaine in this study.

\section{Discussion}

In our study timing of local infiltration was found to be insignificant, i.e. similar pain scores were obtained with both preincisional and preclosure infiltration of bupivacaine. This is in contrast to study conducted by Sarac et al who demonstrated the optimum timing for giving local anaesthetic agent and concluded that local anesthesia infiltration of trocar sites following surgery offers better pain relief than local anesthetic given just before the incision. ${ }^{[6]}$

The timing of giving first analgesic dosage in our study group was significantly less as compared to the control group, this is consistent with the studies carried out by Maharajan et al. ${ }^{[7]}$ We find an appreciable difference in total postoperative analgesic requirement between control group, bupivacaine group and it was consistent with the findings of Bisgaard et al. ${ }^{[8]}$

In our study we found that instillation of bupivacaine at port sites did not have much effect on the post-operative stay. Paulson $\mathbf{J}$ et al, ${ }^{[9]}$ found that patients receiving bupivacaine at any time during the surgery were more likely to go home on the day of procedure $(79 \%$ vs $43 \%$, respectively: $\mathrm{P}<$ 0.02). Similarly, Yu-Yin Liu et al, ${ }^{[10]}$ indicated that infiltrating ropivaciane after surgery through the port site reduce pain intensity, number of patients requiring postoperative analgesics, and hospital stay. The LA group had a significantly shorter hospital stay than the control group $(1.1 \pm 0.3 \mathrm{~d}$ vs $2.8 \pm 2.7 \mathrm{~d}, \mathrm{P}=0.001)$. Longer duration of hospitalization in our study can be attributed to other factors related to the surgery, i.e. all patients are inserted abdominal drains as a standard protocol \& in our wards removal of the drain is done at the 2 nd to 3 rd day post operatively. However, individually some patients were discharged on the same day in both the study groups. 


\section{Groups}

Postoperative shoulder tip pain was observed equally in all the three groups. There was no overall statistically significant difference in the occurrence of shoulder tip pain. Pavlidis et $\mathrm{al}^{[11]}$ studied the effect of local anaethetic ropivaciane at the trocar sites and obtained similar results with an unchanged incidence of shoulder tip pain. In our study we did not observe any side effects of bupivacaine which is in consistent with the study of Narchi et al, ${ }^{[12]}$ who also in their study found no signs of local anesthetic toxicity.

\section{Conclusion}

To conclude, instillation of bupivacaine at the port sites in laparoscopic cholecystectomy irrespective of the timing of instillation is an effective method of achieving pain control in the post-operative period as long as 24 hours after surgery. This technique is simple, safe and without adverse effects and local anesthetics should be considered for instillation in all patients at the beginning and at the end of laparoscopic procedures. It is likely to be cost effective, because it decreases post-operative usage of NSAIDS or opioids, and helps in better resource utilization for treatment of postoperative pain and also useful for patient to provide a more comprehensive and comfortable post-operative period.

\section{References}

1. Kehlet $\mathrm{H}$, Holte $\mathrm{K}$ Effect of postoperative analgesia on surgical outcome. Br J Anaesth 2001;87:62-72.
2. Alexander JI. Pain after laparoscopy. Br J Anesth 1997; 79:369-78.

3. Michael A.E. Ramsay. Acute postoperative pain management. Proc (Bayl Univ Med Cent) 2000; 13(3):244-7.

4. Likar R, Kppert W, Blatnig H. Efficacy of peripheral morphine analgesia in inflamed, noninflamed and perineural tissue of dental surgery patients. J Pain Symptom Manage 2001;21:330-7.

5. Moiniche S, Kehlet H, Dahl JB. A qualitative and quantitative systematic review of preemptive analgesia for postoperative pain relief: the role of timing of analgesia. Anesthesiology 2002;96:725-41.

6. Sarac Murrat A, Baykan N. The effect and timing of local anesthesia in laparoscopic cholecystectomy. Surg laparosc Endosc 1996;6(5):362-6

7. Maharjan SK, Shrestha S. Intraperitoneal and periportal injection of bupivacaine for pain after laparoscopic cholecystectomy. Kathmandu Univ Med J (KUMJ) 2009;7(25): 50-3.

8. Bisgaard T, Klarskov B. Multi-regional local anesthetic infiltration during laparoscopic cholecystectomy in patients receiving prophylactic multi-modal analgesia: a randomized, double-blinded, placebo-controlled study. Anesth Analg 1999;89(4):1017-24.

9. Paulson J, Mellinger $\mathrm{J}$, Baguley $\mathrm{W}$ The use of intraperitoneal bupivacaine to decrease the length of stay in elective laparoscopic cholecystectomy patients. Am Surg 2003;69(4): 275-8.

10. Yu-Yin Liu, Chun -Nan Yeh, Hsiang-Lin Lee, Shang-Yu Wang, Chun-YiTsai, Chih-Chung Lin, Tzu-Chieh Chao, Ta-Sen Yeh, and YiYin Jan. Local Anesthesia with ropivacaine for patients undergoing laparoscopic cholecystectomy. World J Gastronerol 2009;15(19):2376-80.

11. Pavlidis TE, Atmazidis KS, Papaziogaas BT, Makris JG, Lazaridis CN, Papaziogas TB. The effect of preincisional periportal infiltration with ropivaciane in pain relief after laparoscopic procedures: a prospective, randomized controlled trial. Journal of the Society of laparoendoscopic Surgeons 2003;7(4):305-10.

12. Narchi, Benhamou D, Bouaziz H, Fernandez H, Mazoit JX. Serum concentrations of local anaesthetics following intraperitoneal administration during laparoscopy. Eur J Clin Pharmacol 1992;42(2): $223-5$.

Copyright: (C) the author(s), 2019. It is an open-access article distributed under the terms of the Creative Commons Attribution License (CC BY 4.0), which permits authors to retain ownership of the copyright for their content, and allow anyone to download, reuse, reprint, modify, distribute and/or copy the content as long as the original authors and source are cited.

How to cite this article: Chhakarvarty N, Chhabra U, Singh V, Singhal G. Assessment of Pain Outcome and Amount of Analgesic Required Post Operatively After Instillation of Bupivacaine amongst Pre Incisional Vs. Postincisional Vs. Control Groups. Asian J. Med. Res. 2019;8(4):SG06-SG09.

DOI: dx.doi.org/10.21276/ajmr.2019.8.4.SG3

Source of Support: Nil, Conflict of Interest: None declared. 